\title{
Bamboo Paper Production and Religious Use by the Lanten Yao in Northern Lao PDR
}

\author{
Claudio O. Delang
}

\section{Photo Essay}

\begin{abstract}
This photo essay demonstrates the method of producing bamboo paper by the Lanten Yao in northern Lao PDR and discusses the roles of bamboo paper in religious ceremonies. While in the past bamboo paper is likely to have had several uses in Lanten society, the use of bamboo paper is now limited to religious activities, where it cannot be replace by any other material.
\end{abstract}

\section{The Lanten Yao}

The Yao are divided into several ethnic sub-groups, distinguished by differences in language, dress and customs. They originate from China, but their search for farmland and better opportunities have brought many of them to the Lao PDR, Thailand and Vietnam. In China, the Lanten Yao can be found in the provinces of Hainan, Guangxi and Yunnan; in Vietnam, in all the northern provinces; and in the Lao PDR, in the northern provinces of Phongsaly, Oudomxai, Luang Namtha and Bo Kaeo.

There are two sub-groups of Yao in the northern Lao PDR; the highland Yao and the valley Yao, which are known locally as Yao and Lanten respectively. The 1995 census recorded 22,695 Yao in the Lao PDR, within which the Lanten number at least 10,000. In Lao PDR the Lanten are further divided into two groups: Kim Di Mun (of the mountain foot) and Kim Diang Mun (of the mountain top). Chazée (1999) reported that in 1995 there were some 4,500 Kim Di Mun in Luang Namtha, Bokeo and Oudomxai. Since 1975 the official name of the Kim Di Mun used by the government of Lao PDR has been that of Lao Huay. The Lanten interviewed maintain that their name is Lanten and their nickname is Lao Huay. The name Lao Huay (roughly translated as "Lao of the brooks") comes from their custom of living close to brooks. Even though this custom is common among many other ethnic groups, associating them with their ecological niche provides them with a particular identity they seem to like. This photo essay deals with the Lao Huay and describes the method they use to produce paper from bamboo, a grass that is fairly common in the ecological niche where they live. The fieldwork was carried out in February 2006 in two Lanten Yao villages (Nam Dee and Hong Luei) a few kilometers north of Luang Namtha, in Northern Lao PDR (Fig. 1).

Bamboo paper is closely associated with the Lanten religion since no other paper can be used in their religious activities. The Lanten Yao religion consists of a blending of exorcistic and healing rituals for the living in the Meishan traditions, and Taoist rituals for the dead (Lenoine 2002). Bamboo paper is used to make the books on which rituals are written and reproduced, streamers for the dead, masks used in religious ceremonies, to decorate altars, and so forth. Lenoine (2002: 24) has described the role of bamboo paper as "Its ritual value lies in the fact that it can

\section{Correspondence}

Claudio O. Delang, Centre for Southeast Asian Studies, Kyoto University, 46 Shimoadachi-cho, Yoshida, Sakyo-ku, Kyoto 6068501, JAPAN

delang@cseas.kyoto-u.ac.jp

Ethnobotany Research \& Applications 4:097-102 (2006) 


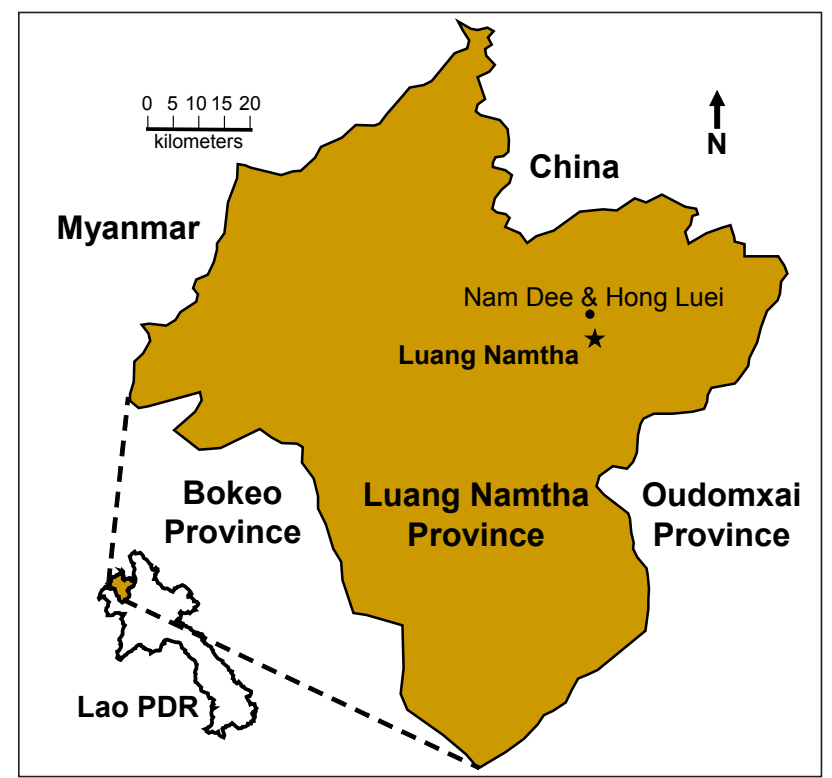

Figure 1. Nam Dee and Hong Luei villages in Luang Namtha Province, Lao PDR.

be burned, and so exchanged with the unseen, the spirit part of the phenomenal world." Only bamboo paper can be used for the religious ceremonies, and while the ceremonies are all carried out by men, the production of bamboo paper is the realm of the women. This is the contribution of the women to the ritual life, together with preparing the food for the men who carry out the rituals, and their guests.

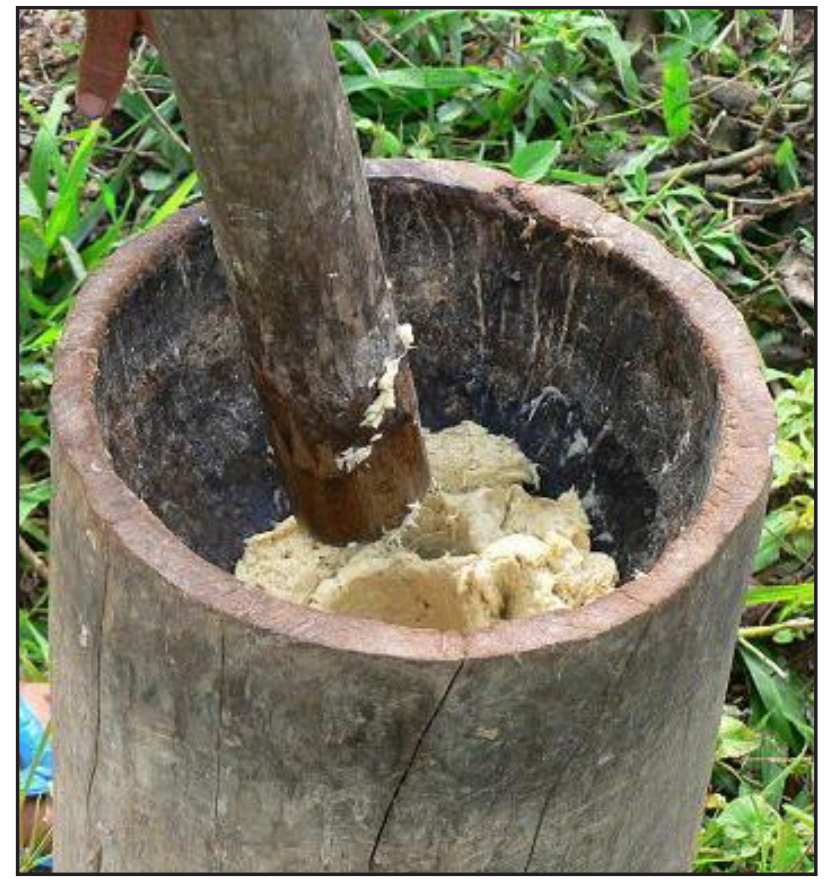

Figure 2. Softened bamboo being crushed with a mortar and pestle.

\section{The Production of Bamboo Paper}

Any kind of bamboo can be used, but usually no bong (cf. Bambusa tulda Roxb.) is used because it produces stronger and whiter paper. After collecting the bamboo, the green, outer layer of the stem is peeled off and only the inside is retained for use. The bamboo is then cut into slices approximately one finger wide and 20 to $30 \mathrm{~cm}$ long.

The pieces of bamboo are then put into a plastic container and alternately layered with calcium oxide until the container is full. Water is then added and the container is covered with three layers of banana leaves (or other large leaves or plastic sheets). Stones are put on top to prevent pigs or chickens from searching the container for food.

The container is left untouched for 1.5 to 2 months. It is then opened and the bamboo extracted. After washing, the bamboo pieces are returned without calcium oxide to the covered container. After 10 days the bamboo is checked to see if it is sufficiently soft. If the bamboo is soft, it is removed from the container and crushed in a mortar (Fig. 2).

When the bamboo has been crushed into a paste, it is placed in a larger wooden or plastic container to which stream water is added. It is then mixed well with a stick or by hand to suspend the particles of bamboo in the water. Large pieces of bamboo that still remain are discarded (Fig. 3). Smaller pieces are removed either by hand or with the prongs of a bamboo fork (Fig. 4). To this water is added a gluing agent, the sap of the tree kok tieng saa.

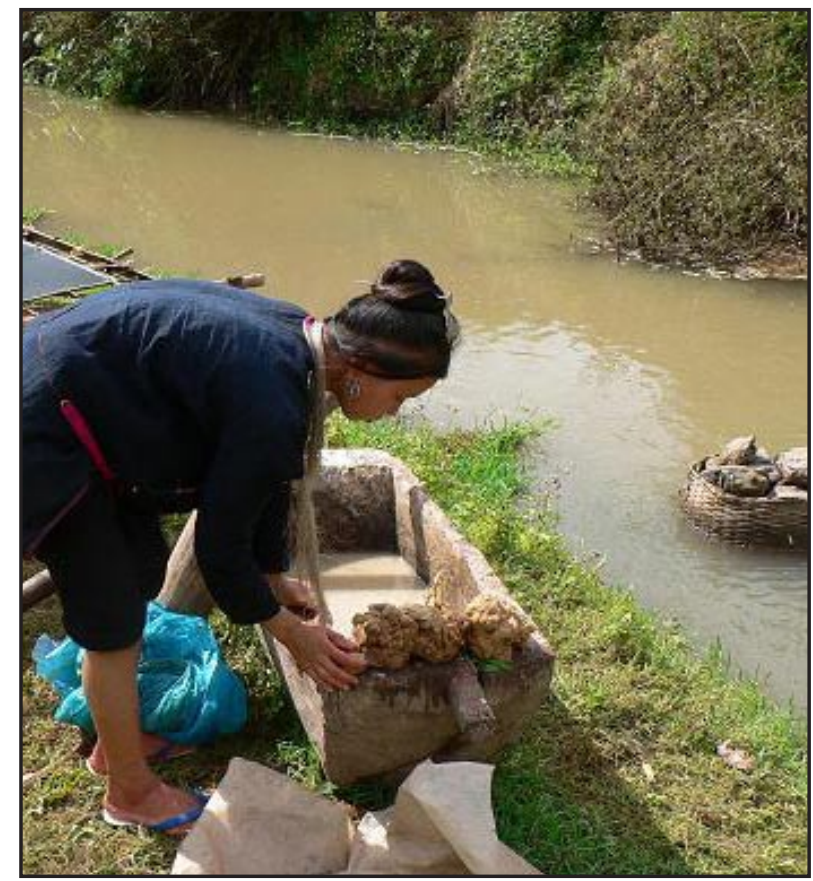

Figure 3. Large pieces of bamboo being removed from a suspension of bamboo fibers in water. 

and Religious Use by the Lanten Yao in Northern Laos

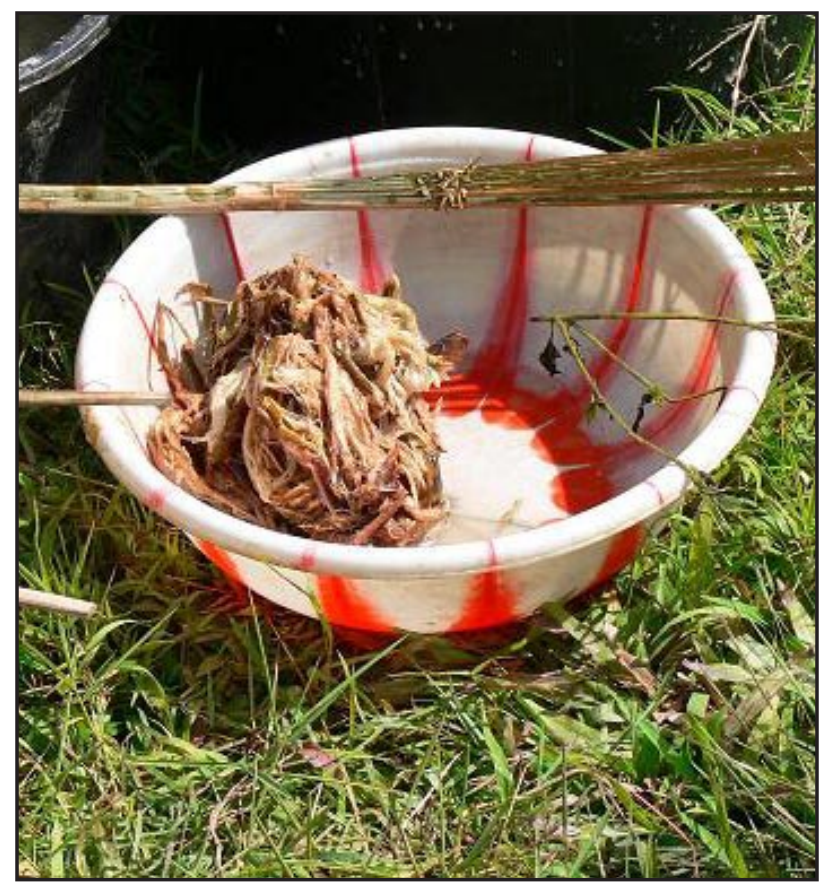

Figure 4. A bamboo fork used to remove small pieces of bamboo.

A branch of the tree kok tieng saa has its outer bark peeled off (Fig. 5). The inner bark is then washed, and beaten with a stick to soften it and facilitate its removal from the stem (Fig. 6). The hard stem is discarded and the bark is further beaten soft (Fig. 7). The bark is then washed with water and its sap is squeezed out by hand (Fig. 8). The sap of the kok tieng saa is viscous, and glues together the particles of bamboo in the water.

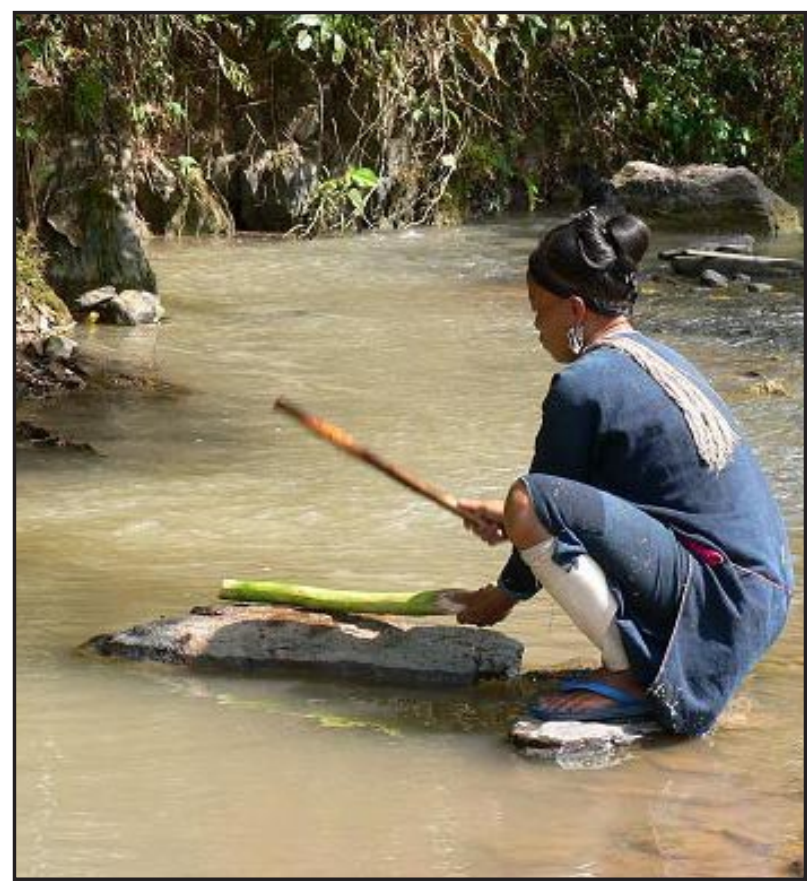

Figure 6. Beating the inner bark of the kok tieng saa tree in order to soften it.

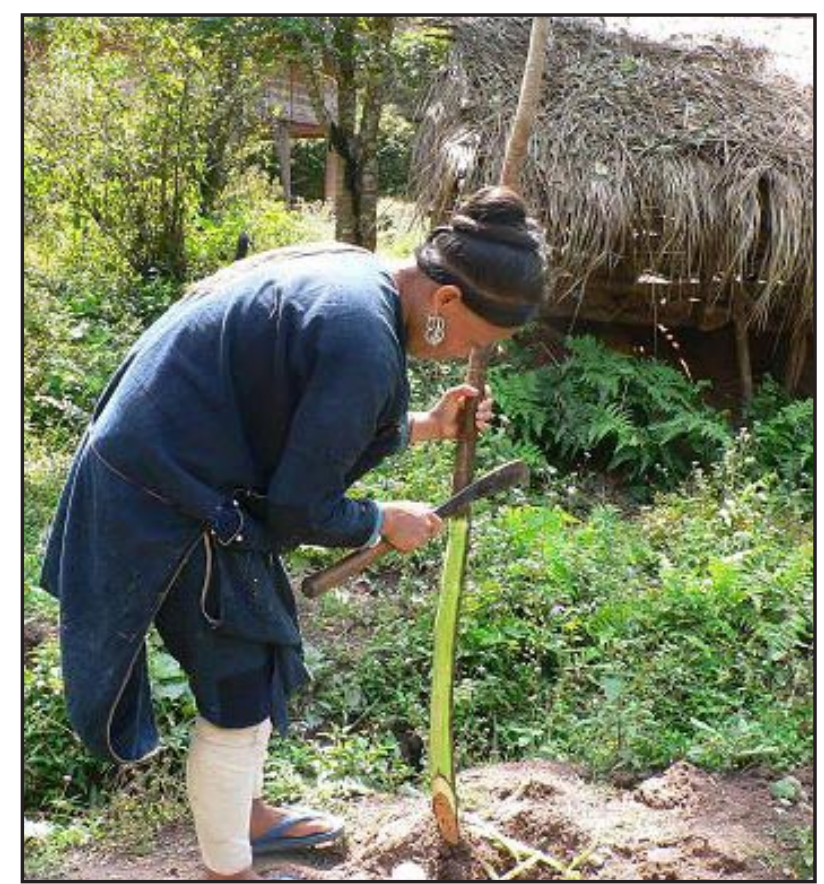

Figure 5. Peeling bark off of a branch of the tree kok tieng saa.

The two liquids (one with the sap from the kok tieng saa tree and one with the bamboo particles) are mixed in appropriate proportions to make the paper slurry. Slurry viscosity is verified with the help of a scoop (Fig. 9). If the liquid is not sufficiently viscous, more liquid from the kok tieng saa is added. The resulting liquid is then ready to be spread over a black woven cloth, tightly drawn over a bamboo frame.

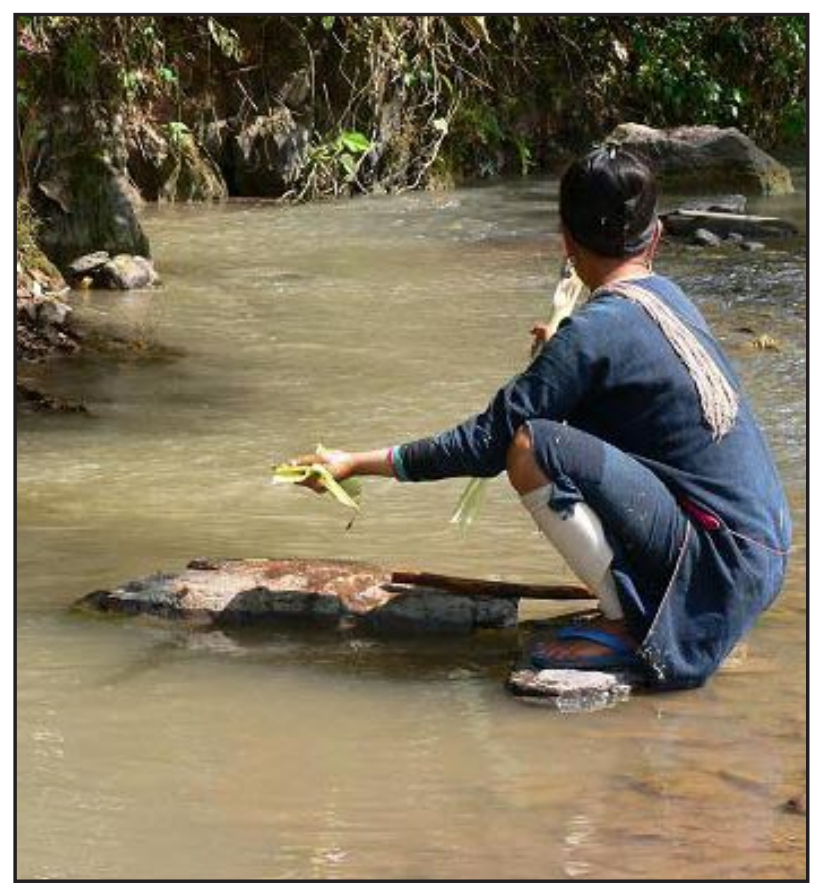

Figure 7. Discarding the stem before further beating the bark. 


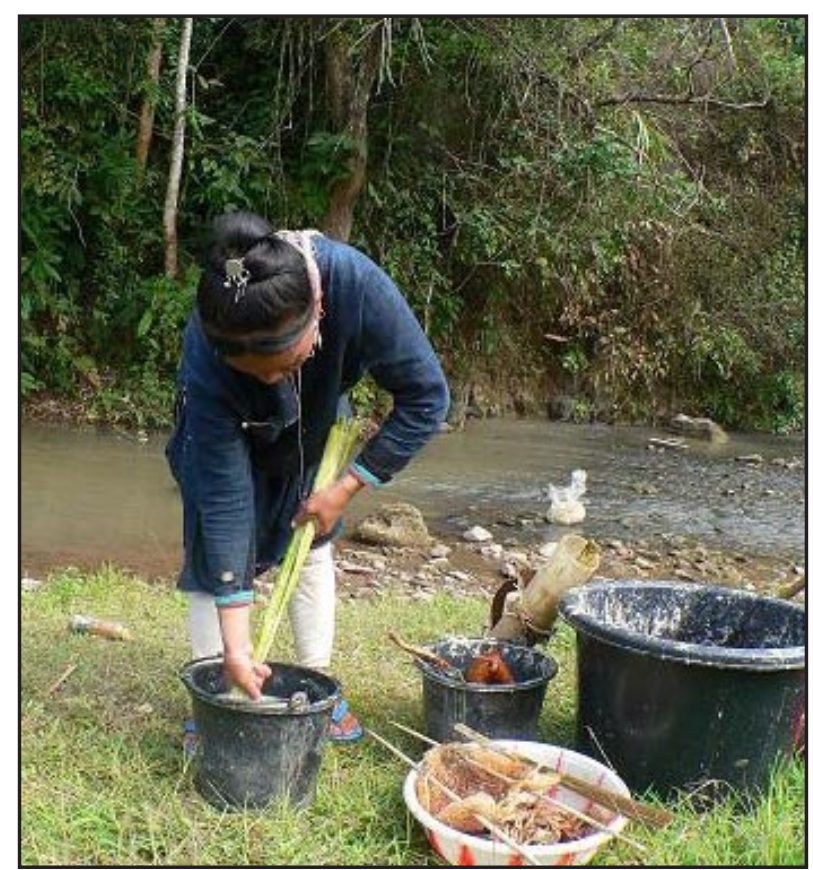

Figure 8. Squeezing sap out of kok tieng saa bark.

Every household produces woven cloth from home-grown cotton. While in the past each household removed the seeds from the fiber by hand, a very time consuming activity, one household in Nam Dee village now does this with a machine for all Lanten in Luang Namtha province. Nevertheless, in general, every household makes the cotton yarn and weaves its own cotton cloth, mainly for the production of clothes. The cloth is woven in narrow strips

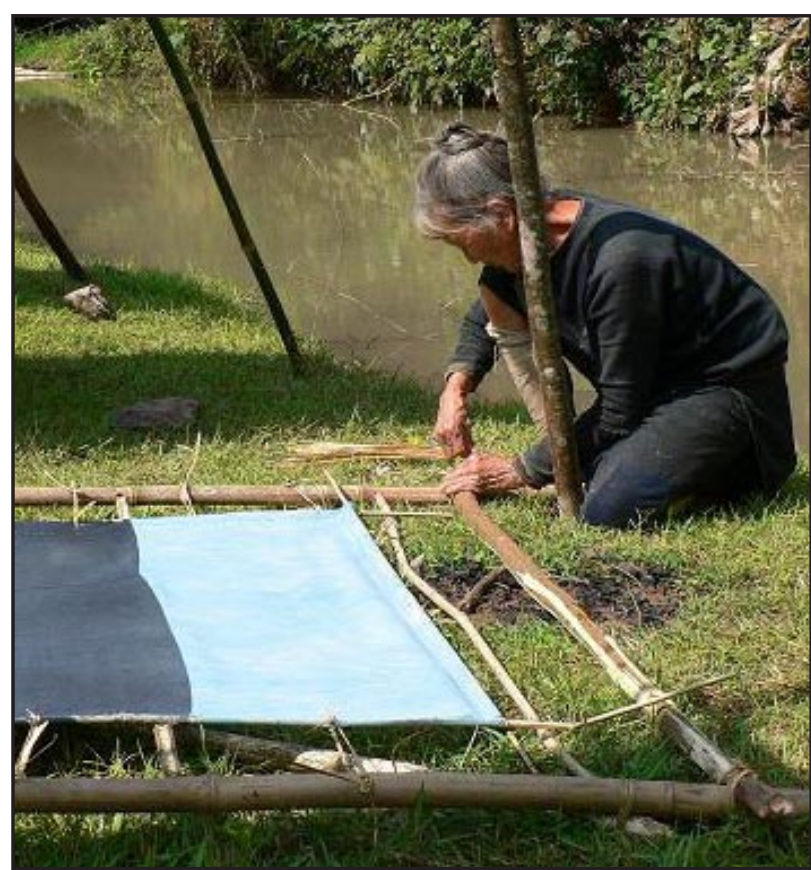

Figure 10. Cloth on a bamboo frame used for paper production.

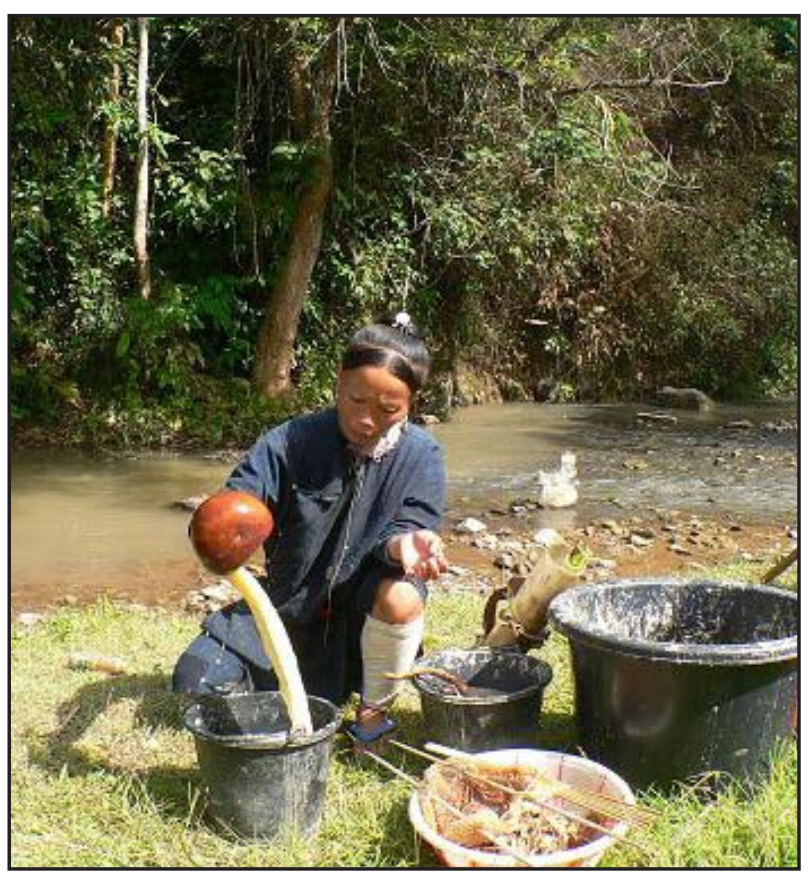

Figure 9. Checking the viscosity of the paper slurry with a scoop.

several meters long and less than one meter wide. Therefore, for the production of bamboo paper, the Lanten sew two pieces of cloth together to make a surface that is approximately $2.25 \mathrm{~m}^{2}$. The cloth is stretched and attached using rattan or bamboo to a bamboo frame (Fig. 10).

The cloth is first washed in the river (Fig. 11). After this, the liquid slurry, consisting of the bamboo particles and

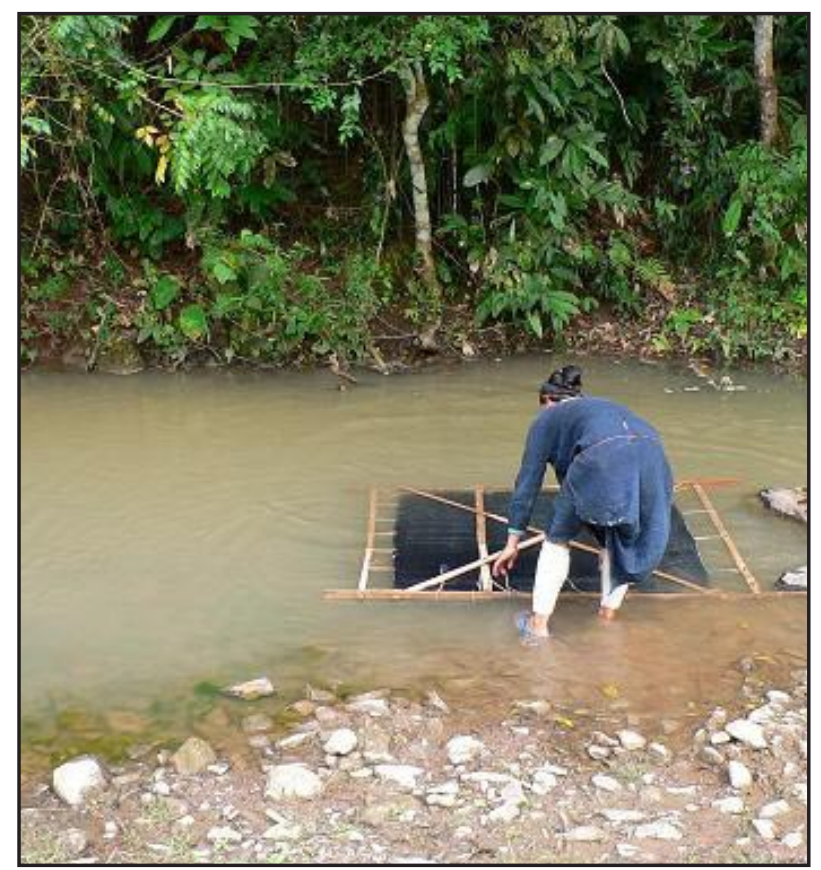

Figure 11. Washing the cloth used for paper making. 
Delang - Bamboo Paper Production

and Religious Use by the Lanten Yao in Northern Laos

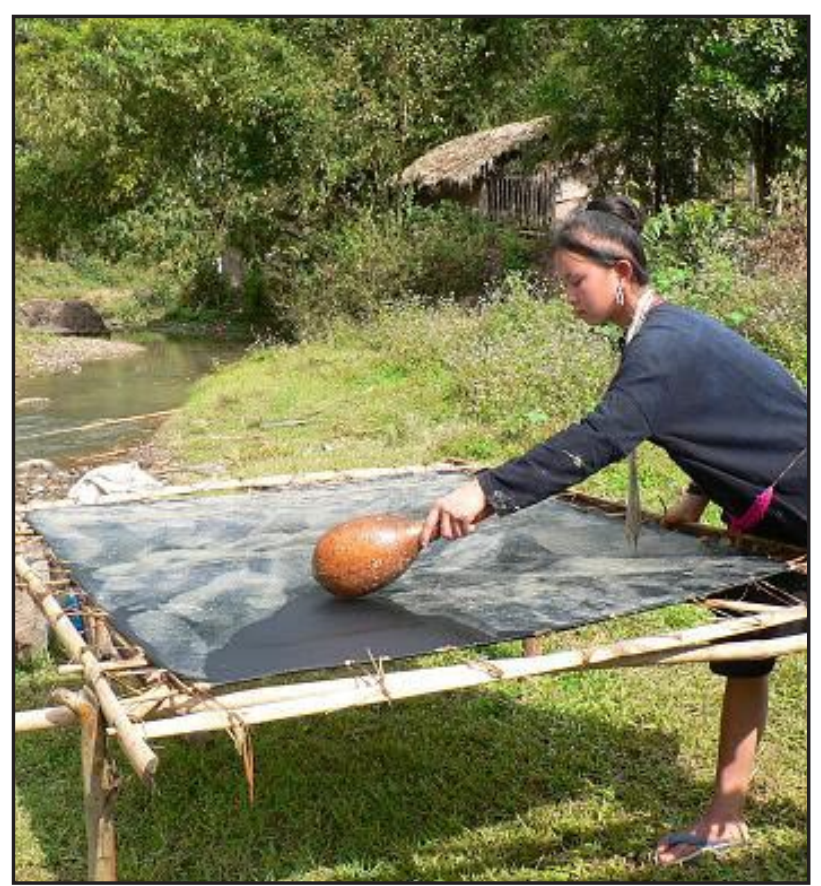

Figure 12. Gourd scoop being used to spread the paper slurry.

the sap, is spread over the woven cloth with a scoop (often made from a gourd) (Fig. 12). All gaps are carefully filled to make sure that the paper has no holes (Fig. 13).

The bamboo paper is left in the sun to dry for a few hours (Fig. 14). When it is dry, it is carefully peeled off the cloth

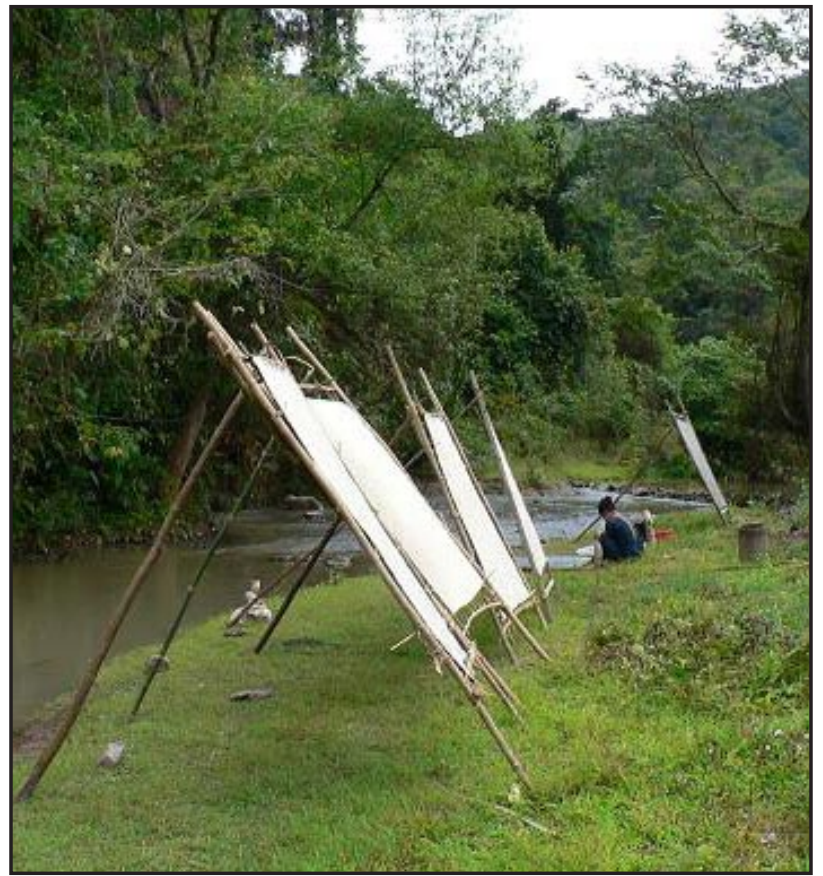

Figure 14. Fresh bamboo paper drying in the sun.

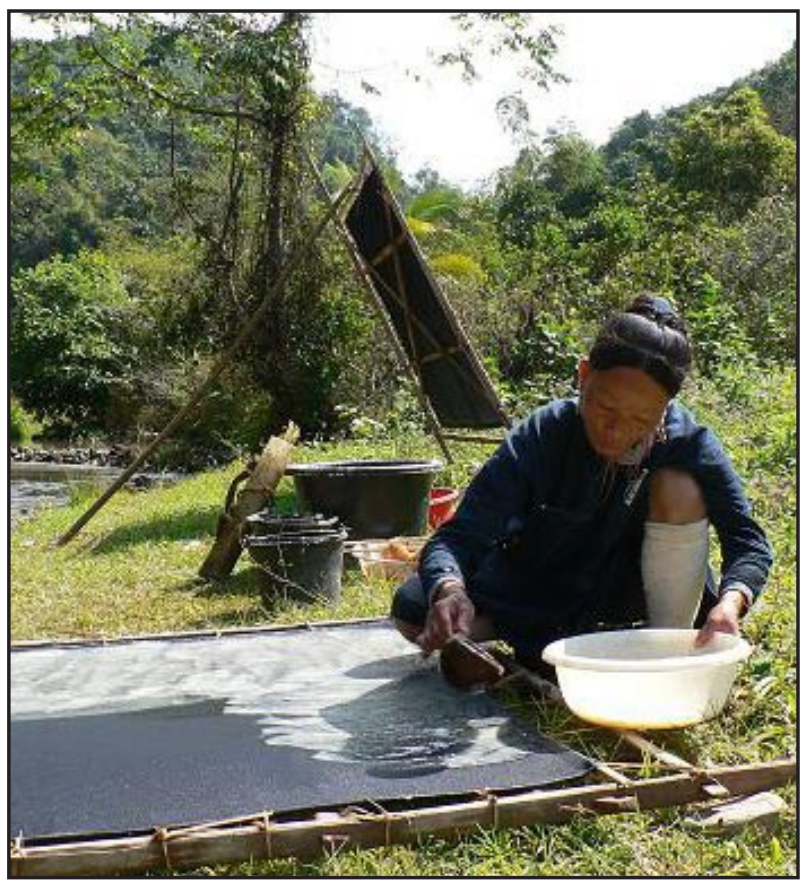

Figure 13. Uniformly spreading paper slurry to ensure that the resulting paper has no holes.

(Fig. 15) and folded for storage. Each piece of paper can be sold for 3,000 to 4,000 kip (US\$0.30 to 0.40). However, many households do not purchase, but produce their own paper.

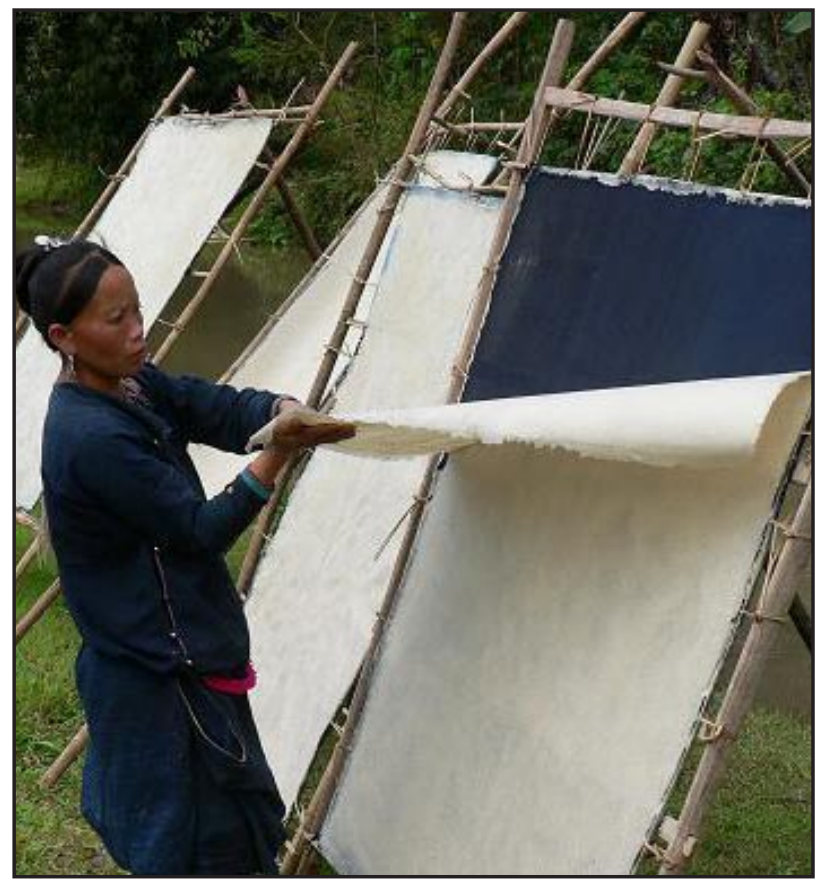

Figure 15. Peeling off freshly made bamboo paper from the drying rack. 


\section{The Role of Bamboo Paper in Lanten Yao Religion}

While in the past the bamboo paper might have been used for other purposes, nowadays, the only use of bamboo paper is religious. Three uses in particular are important, and no other paper except bamboo paper can be used for these purposes.

First, the paper is burned to propitiate the spirits, in the same way that the Chinese burn paper money (paper with a nominal value that they purchase) during the Hungry Ghosts festival (in the seventh lunar month). In some cases, the Lanten write on the bamboo paper before it is burned, but this is not essential.

The second use of bamboo paper is for books that describe religious rituals to be followed. Since the culture originated in China, these Lanten books are written in Chinese using Chinese characters. However, since schooling in the Lao PDR is in the Lao language, only elders can read the books.

The third and probably most demanding use of bamboo paper is for decoration of ceremonial altars and the paper curtains used during religious ceremonies. Huge paper curtains are erected by households for a memorial ceremony for their ancestors (Lemoine 2002). This ceremony lasts for three full days and nights. All kin, as well as virtually all the fellow villagers, are invited to participate at least in the great collective meals. One hundred and fifty bamboo paper sheets might be used during one such

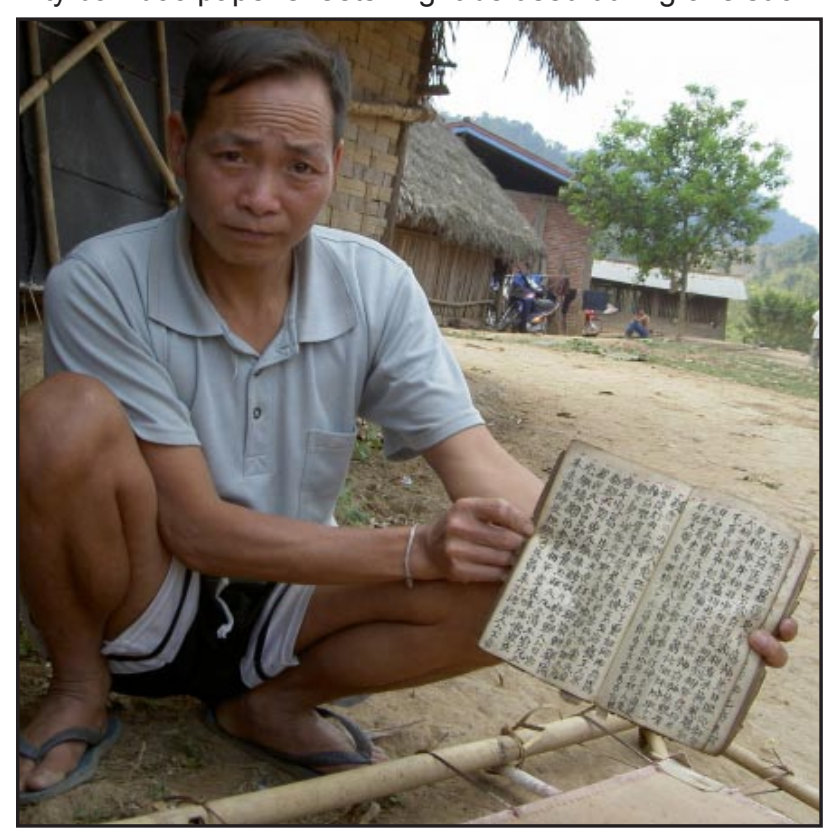

Figure 16. A household head shows one of the books, which he said is several decades old and he inherited from his grandfather. ceremony. This, accompanied with the food that has to be offered to guests, accounts for one of the largest yearly expenditures of a household.

\section{Conclusions}

Religious events are the only ceremonies where the whole village - the haves and the have nots - participate. As such they are important in cementing the social fabric in Lanten villages. The Lanten might move from one village to another, according to the particular circumstances of their life-cycle, but they will always stay in a Lanten environment. Religion is the final barrier of their ethnic frontier, and as such, it might be the most treasured part of their cultural heritage. Bamboo paper, as the only paper that can be used in such ceremonies, and - when it is burned - as the means to communicate with the spirits of the phenomenal world, has an essential role in such ceremonies.

\section{Acknowledgement}

The author would like to thank the population of Nam Dee and Hong Luei for their patient explanations of the process of bamboo paper making, as well as the Japanese Societies for the Promotion of Science for its financial contribution towards the costs of the fieldwork.

\section{Literature Cited}

Chazée, L. 1999. The Peoples of Laos: Rural and ethnic diversities. White Lotus, Bangkok.

Lemoine, J. 2002. Social Fabric, Education and HIV Vulnerability Among the Lanten Yao of Muang Long, Luang Namtha Province, Lao PDR. UNESCO-ORACAP, Bangkok. 